\title{
Evaluating the Efficiency of Heat and Power Systems by the Data Envelopment Analysis Method
}

\author{
M POKUSHKO ${ }^{1,3,4}$, A STUPINA ${ }^{1,3}$, I MEDINA-BULO ${ }^{4}$, E DRESVIANSKII ${ }^{2,3,4}$, A STUPIN ${ }^{3,4}$, \\ R KUZMICH $^{1}$, I RUIGA ${ }^{1}$, L KORPACHEVA ${ }^{1}$ \\ ${ }^{1}$ Institute of Business Process Management \\ Siberian Federal University \\ 660041, Krasnoyarsk, Svobodny Ave., 79 \\ RUSSIA \\ ${ }^{2}$ Polytechnic Institute \\ Siberian Federal University \\ 660041, Krasnoyarsk, Svobodny Ave., 79 \\ RUSSIA \\ ${ }^{3}$ Institute of Informatics and Telecommunications \\ Reshetnev Siberian State University of Science and Technology \\ 660037, Krasnoyarsk, Krasnoyarsky rabochy Ave, 31 \\ RUSSIA \\ ${ }^{4}$ Superior Engineering School \\ University of Cadiz \\ 11519, Puerto Real (Cadiz), University of Cadiz Ave., 10 \\ SPAIN
}

\begin{abstract}
The article describes the Data Envelopment Analysis (DEA) method and the main features of its application. The main problems of heat and power systems are described, which are addressed by the DEA method of efficiency assessment presented in the article. The approbation of this method is presented at the objects of the centralized municipal heat supply system of the fuel and energy complex: boiler houses and heat and power plants. 9 objects were analyzed according to four input indicators: available heat capacity, installed heat capacity, heat consumption for own needs, fuel consumption. Also, the efficiency of the system was evaluated according to two output indicators: the release of thermal energy to the grid and the mass of the emission. As a result of the analysis and calculations made, it was revealed that 5 objects have the maximum possible efficiency indicator equal to 1 , that is, they function as efficiently as possible. 4 objects of the centralized municipal heat supply system have an efficiency indicator less than 1. Accordingly, improvements are required for the operation of the above Decision-Making Units (DMU)s. These objects have deviations in terms of the inputs and outputs of the actual data and those obtained using the DEA method. Based on the calculations obtained for these 4 objects, the article provides recommendations for changing the quantitative values of their input and output indicators. For example, for object number 2, it is recommended to reduce the installed heat capacity in the grid by $72.57 \%$, without changing the available heat capacity and fuel consumption. Reduce the heat consumption for your own needs by $69.383 \%$. In addition, it is recommended to increase the supply of thermal energy to the grid by $6,034 \%$, and reduce the mass of emission by $11.5 \%$. Specific measures have also been developed to modernize the studied objects in order to achieve the recommended indicators of inputs and outputs. The research results presented in the article are of scientific and practical interest and can be used to improve the efficiency of heat and power systems facilities.
\end{abstract}

Key Words: - fuel and energy complex, heat and power system, centralized municipal heat supply system, methodology, the Data Envelopment Analysis method, decision making unit, complex system, efficiency indicators.

Received: February 3, 2021. Revised: August 17, 2021. Accepted: August 30, 2021. Published: September 2, 2021.

\section{Introduction}

A significant increase in the production and consumption of energy resources, the depletion of natural sources in the absence of the possibility for their renewal, and in this regard, the increase in prices for electricity, water, heat makes us take a 
new look at solving the problem in the efficiency of their use and the work of enterprises producing and processing such resources. All this determines the importance of scientific research to improve the efficiency of technical systems in the fuel and energy complex.

In modern conditions of rapid technological development, it is necessary to evaluate the efficiency of heat and power systems and develop and implement an interdisciplinary approach related to considering various aspects of the latest developments when assessing the effectiveness of complex systems with a large set of parametric indicators. This increases the importance and interest in new approaches to the mechanical design of heat and power systems of the fuel and energy complex when optimizing their main parameters.

Global trends in scientific and technological development orient modern fuel and energy sector organizations to carry out activities to improve the efficiency of the enterprise, corresponding to modern principles of activities organized and the best international practices. And also, to increase competitiveness, it is necessary to ensure the transition to advanced digital, intelligent production technologies that help to increase the efficiency of modern fuel and energy enterprises.

One of the most problematic, requiring modernization and technical development, is the centralized municipal heat supply of the fuel and energy complex. Their functioning is a very complex and time-consuming process, the effectiveness of which is often not evaluated systematically in practice by organizations due to the presence of a large set of parametric indicators. Such calculations are quite difficult to carry out without the use of computer technology and modern programming technologies. In this regard, it is possible to evaluate the efficiency of the fuel and energy complex's centralized municipal heat supply system and develop recommendations for further optimization of such a system.

There are several methods for evaluating the effectiveness of complex systems. In previous publications, we conducted a comparative analysis of them, from which we concluded that the maximum effectiveness of using the DEA method in solving problems in these articles $[1,2]$. By this, it seems possible to form a methodology for evaluating the effectiveness of complex hierarchical systems for centralized municipal heat supply of the fuel and energy complex based on the DEA method.

\section{Problem Formulation}

When operating complex technical systems, various problems arise that require analyzing a large array of parametric data.

This is why the emergence of a new methodology for evaluating technical systems using computer and programming technologies. In this regard, it has recently become quite relevant to consider the solution of technical problems using system analysis methods.

The orientation of the management concept of any organization on the productivity and efficiency of its activities requires the use of best practices for evaluating business metrics, which forms a set of new approaches to understanding the organization's activities quality and, consequently, its viability. In addition, this concept reflects the efficiency of the studied system during the conversion of certain inputs into outputs.

In solving practice-oriented management tasks, the analysis of complex systems functioning has become widespread due to the presence of direct dependence of improving the effectiveness of planning and management in various fields of activity on the study of such systems effectiveness, while observing the main criterion: making decisions relevant to certain conditions in which the reproduction process of system objects is carried out. Therefore, studying the effectiveness of the complex system in all spheres of human activity has received increased attention in recent years. Depending on the subject area of the study, different approaches are used. However, many methods have been developed that are used to evaluate the effectiveness of objects in a reasonably wide class of technical systems.

For example, in [15], scientists describe the possibility of applying the knowledge obtained so far about bounded additive models to construct models of the directed distance function in DEA. These assumptions give rise to a completely new type of limited and partially limited models and test a new approach on a real set of agricultural panel data. This article is continued in the research of another group of scientists [7].

The researches of Takano et al. [16] are devoted to one of the directions of resource 
allocation in complex systems. Shao et al. [17] also suggest applying the DEA method to evaluate the effectiveness of a grid of branches in a large enterprise with a centralized management structure.

In their article [18], scientists introduce the DEA approach to search for the most effective information system projects, considering the subjective opinions and intuitive feelings of decision-makers. The first studies in this area were conducted a little earlier in [19]. The approach proposed in the article is confirmed by a real practical study on the example of a large financial institution, where various information projects of the enterprise were analyzed.

The choice of the DEA model depends on the number of input and output variables. This conclusion is made by the above-mentioned authors, and this idea is also developed by Branda $\mathrm{M}$ and Kopa $\mathrm{M}$ in their study [20]. This can be avoided by reducing the dimension of the variables. But since the lost information can also affect the effectiveness of the assessment, Xie et al. [21] describe a new approach to increase the discriminatory power of DEA without losing any information about variables and without the need for any additional preferential information [22].

Many Russian [23, 24] and foreign [25, 26] authors believe that to obtain a more reasonable assessment of the current performance of a complex system and predict its future performance, it is desirable to consider the structure of the system itself.

When a system is hierarchical, to obtain a reasonable assessing the effectiveness of the entire system, it is necessary to consider the effectiveness of subsystems at different levels of the hierarchy. Russian scientists E. P. Morgunov and O. N. Morgunova come to this conclusion in their research [27]. They suggest that it would be advisable to present the procedure for evaluating the efficiency of complex hierarchical systems in a formalized methodology. They propose to build such a methodology based on the DEA method.

\section{Problem Solution}

DEA is a convenient tool that helps measure the production efficiency of the system we are interested in, that is, an organizational unit.
This method is one of the ways to evaluate the production function if the output is not scalar, but vector, or in other words, when several types of products are produced [27].

The DEA method is a boundary method. Since it is based on the construction of the efficiency boundary. This boundary can be represented in the form of a convex hull or a convex cone in the space of points of input and output variables of the studied objects, the studied population. We can say that the efficiency boundary wraps around, or wraps around the points corresponding to the studied objects in multidimensional space. The efficiency boundary is used as a reference ("reference point") to obtain a numerical value for evaluating the effectiveness of each of the objects in the studied population. The degree of objects proximity to the efficiency boundary in the multidimensional space of inputs and outputs determines the degree of efficiency of the analyzed objects. The points lying on the efficiency boundary are the most effective objects.

The construction of the efficiency boundary is carried out by repeatedly solving the linear programming problem [27].

The system for which the comparative efficiency is evaluated is called a module (unit) or Decision-Making Unit (DMU) [28]. The DMU uses certain resources at the input and converts them into products of a specific type at the output. The process diagram is shown in figure 1.

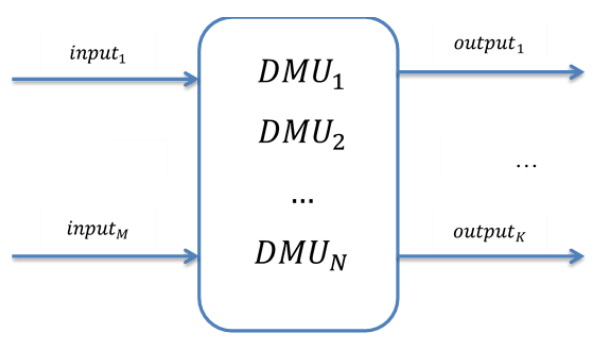

Fig.1: Diagram of converting DMU inputs to outputs.

The DEA method applies to various spheres of human life, namely: financial, logistics, industrial, and so on. Based on the broad applicability, we can distinguish quite essential 
features of the DEA method. Each DMU is assigned one value that characterizes the relative efficiency of this unit. Effective units act as a standard for inefficient ones.

All DEA models can be classified according to two criteria [29]:

1) Orientation of the model.

2) The return to scale of the model.

The formula (1) by which the efficiency value is calculated according to the DEA model [3] is given below:

$$
0 \leq \text { Efficiency }_{\mathrm{Z}}=\frac{0 \mathrm{Z} 1}{0 \mathrm{Z}} \leq 1
$$

Its value is always in the range from 0 to 1 .

In previous articles [1,2], the methodology of the proposed DEA method was described in detail, and the process of forming an effective efficiency assessment model using a decision support system with the DEA method was considered, the concept of a complex system and its features were considered.

There are the following types of model orientation: input-oriented models and outputoriented models.

There are two types of returns to scale of the model: constant returns to scale and variable returns to scale [30]. Both models described above are divided into models with constant returns to scale (CRS) and variable returns to scale (VRS), the return to scale, depending on the impact of the objects activities scale on efficiency growth.

In this publication, a complex system is selected for testing the method - the centralized municipal heat supply system in the city of Krasnoyarsk, and the efficiency of its facilities will be analyzed.

The functioning of the centralized municipal heat supply system is a very complex and timeconsuming process that requires a rational approach to the use of available resources. To assess the effectiveness of such a process, it is proposed to assess the effectiveness of complex hierarchical systems based on the DEA method. This method will contain indicators of optimal parameters for all values of the system's inputs and outputs.
Next, we will consider the problem for DMU objects of the centralized municipal heat supply system (heat and power plants and boiler houses), using four input indicators and two output indicators.

As input indicators, we use:

1. Available heat capacity (Gcal/hour).

2. Installed heat capacity (Gcal / h).

3. Heat consumption for own needs ( $\mathrm{Gcal} / \mathrm{h})$.

4. Fuel consumption (thousand tons of standard fuel).

As output indicators, we use:

1. Supply of heat energy to the grid (thousand Gcal).

2. Mass of emission (thousand tons per year).

Set a goal - to increase the output volume without increasing the input, that is, at a certain power of each DMU equipment. We need to increase the amount for the supply of heat energy to the grid and reduce the number of emissions, or, what is the same, increase the deviation of the emissions mass from the threshold value.

The Data Envelopment Analysis Program (DEAP) software of New England University in Australia, Professor T. Coelli, was used for calculations [3].

Based on the project "Heat supply scheme of Krasnoyarsk until 2033", objects of the city's centralized municipal heat supply system were analyzed, and observations were conducted for three years.

When calculating performance indicators, the output-oriented DEA model is used. This article will describe a problem with four inputs and two outputs.

As in previous publications, we will solve an output-oriented task.

This study will use a variable return on scale [3] since the data set is quite heterogeneous and has a large spread. As a result, the coefficient of variation is significantly higher than $33 \%$.

Based on the results of the calculations, we will form table 1, which will contain the initial data of the object indicators - DMU and the values of the recommended values of the input and output indicators for all the considered objects. 
The input indicators are indicated in the table as INPUT (x). The output indicators are presented in the table as OUTPUT (y).

Table 1 shows the initial values for the analyzed indicators.

Table 1. Source data - a list of DMUs, inputs, outputs.

\begin{tabular}{|c|c|c|}
\hline \multirow{2}{*}{$\begin{array}{c}\begin{array}{c}\text { Department } \\
\text { (DMU) }\end{array} \\
\text { Inputs and outputs }\end{array}$} & \multicolumn{2}{|c|}{ Performance indicator } \\
\hline & $\begin{array}{c}\text { The } \\
\text { initial } \\
\text { value }\end{array}$ & $\begin{array}{c}\text { The } \\
\text { recommended } \\
\text { value }\end{array}$ \\
\hline \multicolumn{3}{|c|}{ Object 1} \\
\hline $\begin{array}{ll}\text { Available } \\
\text { capacity }\end{array}$ & 57.6 & 57.6 \\
\hline $\begin{array}{l}\text { Installed heat } \\
\text { capacity }\end{array}$ & 89.00 & 89.00 \\
\hline $\begin{array}{l}\text { Heat consumption } \\
\text { for your own needs }\end{array}$ & 1.2 & 1.2 \\
\hline Fuel consumption & 28.50 & 28.50 \\
\hline $\begin{array}{l}\text { Supply of heat } \\
\text { energy to the grid }\end{array}$ & 98.95 & 98.95 \\
\hline Mass of emission & 20160.40 & 20160.40 \\
\hline \multicolumn{3}{|c|}{ Object 2} \\
\hline $\begin{array}{l}\text { Available heat } \\
\text { capacity }\end{array}$ & 153.20 & 153.20 \\
\hline $\begin{array}{ll}\text { Installed heat } \\
\text { capacity }\end{array}$ & 570.00 & 156.367 \\
\hline $\begin{array}{l}\text { Heat consumption } \\
\text { for your own needs }\end{array}$ & 8.10 & 2.48 \\
\hline Fuel consumption & 70.30 & 70.30 \\
\hline $\begin{array}{l}\text { Supply of heat } \\
\text { energy to the grid }\end{array}$ & 423,39 & 448,94 \\
\hline Mass of emission & 15210.05 & 16958.43 \\
\hline \multicolumn{3}{|c|}{ Object 3} \\
\hline $\begin{array}{ll}\begin{array}{l}\text { Available } \\
\text { capacity }\end{array} & \text { heat }\end{array}$ & 631.5 & 631.5 \\
\hline $\begin{array}{l}\text { Installed heat } \\
\text { capacity }\end{array}$ & 640.00 & 640.00 \\
\hline $\begin{array}{l}\text { Heat consumption } \\
\text { for your own needs }\end{array}$ & 12.60 & 12.60 \\
\hline Fuel consumption & 589.336 & 589.336 \\
\hline $\begin{array}{l}\text { Supply of heat } \\
\text { energy to the grid }\end{array}$ & 1914.00 & 1914.00 \\
\hline Mass of emission & 9344.018 & 9344.018 \\
\hline \multicolumn{3}{|c|}{ Object 4} \\
\hline $\begin{array}{l}\text { Available } \\
\text { capacity }\end{array}$ & 288.96 & 288.96 \\
\hline $\begin{array}{l}\text { Installed } \\
\text { capacity }\end{array}$ & 295.84 & 295.84 \\
\hline Heat consumption & 1.20 & 1.20 \\
\hline
\end{tabular}

\begin{tabular}{|c|c|c|}
\hline \multicolumn{3}{|l|}{ for your own needs } \\
\hline Fuel consumption & 156.00 & 156.00 \\
\hline $\begin{array}{l}\text { Supply of heat } \\
\text { energy to the grid }\end{array}$ & 442.63 & 442.63 \\
\hline Mass of emission & 21010.73 & 21010.73 \\
\hline \multicolumn{3}{|c|}{ Object 5} \\
\hline $\begin{array}{ll}\text { Available } & \text { heat } \\
\text { capacity } & \end{array}$ & 136.43 & 136.43 \\
\hline $\begin{array}{l}\text { Installed } \\
\text { capacity }\end{array}$ & 139.60 & 139.60 \\
\hline $\begin{array}{l}\text { Heat consumption } \\
\text { for your own needs }\end{array}$ & 2.03 & 2.03 \\
\hline Fuel consumption & 39.60 & 39.60 \\
\hline $\begin{array}{l}\text { Supply of heat } \\
\text { energy to the grid }\end{array}$ & 394.93 & 394.93 \\
\hline Mass of emission & 19752.82 & 19752.82 \\
\hline \multicolumn{3}{|c|}{ Object 6} \\
\hline $\begin{array}{ll}\text { Available } & \text { heat } \\
\text { capacity } & \end{array}$ & 339.85 & 339.85 \\
\hline $\begin{array}{l}\text { Installed } \\
\text { capacity }\end{array}$ & 362.70 & 347.777 \\
\hline $\begin{array}{l}\text { Heat consumption } \\
\text { for your own needs }\end{array}$ & 4.49 & 4.49 \\
\hline Fuel consumption & 135.20 & 111.833 \\
\hline $\begin{array}{l}\text { Supply of heat } \\
\text { energy to the grid }\end{array}$ & 795.6 & 911.76 \\
\hline Mass of emission & 15568.4 & 25561.9 \\
\hline \multicolumn{3}{|c|}{ Object 7} \\
\hline $\begin{array}{ll}\begin{array}{l}\text { Available } \\
\text { capacity }\end{array} & \text { heat }\end{array}$ & 96.60 & 72.02 \\
\hline $\begin{array}{l}\text { Installed } \\
\text { capacity }\end{array}$ & 118.00 & 118.00 \\
\hline $\begin{array}{l}\text { Heat consumption } \\
\text { for your own needs }\end{array}$ & 1.70 & 1.543 \\
\hline Fuel consumption & 33.75 & 33.75 \\
\hline $\begin{array}{l}\text { Supply of heat } \\
\text { energy to the grid }\end{array}$ & 82.83 & 110.94 \\
\hline Mass of emission & 19778.98 & 24922.69 \\
\hline \multicolumn{3}{|c|}{ Object 8} \\
\hline $\begin{array}{ll}\text { Available } & \text { heat } \\
\text { capacity } & \end{array}$ & 373 & 366.57 \\
\hline $\begin{array}{ll}\text { Installed } & \text { heat } \\
\text { capacity } & \end{array}$ & 375.80 & 375.80 \\
\hline $\begin{array}{l}\text { Heat consumption } \\
\text { for your own needs }\end{array}$ & 11.00 & 5.45 \\
\hline Fuel consumption & 106.40 & 106.40 \\
\hline $\begin{array}{l}\text { Supply of heat } \\
\text { energy to the grid }\end{array}$ & 433.39 & 1061.125 \\
\hline Mass of emission & 19290.39 & 27500.8 \\
\hline \multicolumn{3}{|c|}{ Object 9} \\
\hline $\begin{array}{l}\text { Available } \\
\text { capacity }\end{array}$ & 61.6 & 61.6 \\
\hline Installed & 113.80 & 70.36 \\
\hline
\end{tabular}




\begin{tabular}{|c|c|c|}
\hline capacity & & \\
\hline $\begin{array}{l}\text { Heat consumption } \\
\text { for your own needs }\end{array}$ & 1.4 & 1.4 \\
\hline Fuel consumption & 25.25 & 25.25 \\
\hline $\begin{array}{l}\text { Supply of heat } \\
\text { energy to the grid }\end{array}$ & 70.36 & 70.36 \\
\hline Mass of emission & 20768.55 & 20768.55 \\
\hline
\end{tabular}

When solving this problem, it is necessary to reduce part of the output indicators. Namely, it is essential to reduce the mass of emissions for the studied objects, although they should be increased according to the DEA model. This is necessary for solving problems by the DEA method when setting the final goal - reducing the output indicator since, in this case, it is required to reduce the mass of emissions $[3,4]$. In this case, it is required to use the calculations not the values of the objects indicators by the group of emissions themselves, but their deviation from the selected threshold value. Thus, the threshold value is assumed to be equal to 22.000 thousand tons per year. This is the maximum value for this indicator of the emissions mass from all ranked objects, rounded to an integer value.

We will perform calculations using the DEA method. The results obtained are presented in table 2 .

Table 2. Performance indicators $-\mathrm{a}$ list of DMUs, the efficiency coefficient of the object, deviation indicator, difference.

\begin{tabular}{|l|c|c|}
\hline \multicolumn{1}{|c|}{$\begin{array}{c}\text { Department } \\
\text { (DMU) }\end{array}$} & \multicolumn{2}{c|}{ Performance indicator } \\
\hline Inputs and outputs & $\begin{array}{c}\text { Difference } \\
\text { between } \\
\text { values }\end{array}$ & $\begin{array}{c}\text { Difference } \\
\text { in \% }\end{array}$ \\
\hline Object 1 & \multicolumn{2}{|c|}{$\mathbf{1}$} \\
\hline Available heat capacity & 0 & $0 \%$ \\
\hline Installed heat capacity & 0 & $0 \%$ \\
\hline $\begin{array}{l}\text { Heat consumption for } \\
\text { your own needs }\end{array}$ & 0 & $0 \%$ \\
\hline Fuel consumption & 0 & $0 \%$ \\
\hline $\begin{array}{l}\text { Supply of heat energy to } \\
\text { the grid }\end{array}$ & 0 & $0 \%$ \\
\hline Mass of emission & 0 & $0 \%$ \\
\hline Object 2 & 0.943 \\
\hline Available heat capacity & 0 & $0 \%$ \\
\hline Installed heat capacity & -413.63 & $-72.57 \%$ \\
\hline $\begin{array}{l}\text { Heat consumption for } \\
\text { your own needs }\end{array}$ & -5.62 & $-69.383 \%$ \\
\hline
\end{tabular}

\begin{tabular}{|c|c|c|}
\hline Fuel consumption & 0 & $0 \%$ \\
\hline $\begin{array}{l}\text { Supply of heat energy to } \\
\text { the grid }\end{array}$ & 25.55 & $6.034 \%$ \\
\hline Mass of emission & 1748.38 & $11.5 \%$ \\
\hline Object 3 & \multicolumn{2}{|c|}{1} \\
\hline Available heat capacity & 0 & $0 \%$ \\
\hline Installed heat capacity & 0 & $0 \%$ \\
\hline $\begin{array}{l}\text { Heat consumption for } \\
\text { your own needs }\end{array}$ & 0 & $0 \%$ \\
\hline Fuel consumption & 0 & $0 \%$ \\
\hline $\begin{array}{l}\text { Supply of heat energy to } \\
\text { the grid }\end{array}$ & 0 & $0 \%$ \\
\hline Mass of emission & 0 & $0 \%$ \\
\hline Object 4 & \multicolumn{2}{|c|}{$\mathbf{1}$} \\
\hline Available heat capacity & 0 & $0 \%$ \\
\hline Installed heat capacity & 0 & $0 \%$ \\
\hline $\begin{array}{l}\text { Heat consumption for } \\
\text { your own needs }\end{array}$ & 0 & $0 \%$ \\
\hline Fuel consumption & 0 & $0 \%$ \\
\hline $\begin{array}{l}\text { Supply of heat energy to } \\
\text { the grid }\end{array}$ & 0 & $0 \%$ \\
\hline Mass of emission & 0 & $0 \%$ \\
\hline Object 5 & \multicolumn{2}{|c|}{1} \\
\hline Available heat capacity & 0 & $0 \%$ \\
\hline Installed heat capacity & 0 & $0 \%$ \\
\hline $\begin{array}{l}\text { Heat consumption for } \\
\text { your own needs }\end{array}$ & 0 & $0 \%$ \\
\hline Fuel consumption & 0 & $0 \%$ \\
\hline $\begin{array}{l}\text { Supply of heat energy to } \\
\text { the grid }\end{array}$ & 0 & $0 \%$ \\
\hline Mass of emission & 0 & $0 \%$ \\
\hline Object 6 & \multicolumn{2}{|c|}{$\begin{array}{l}1 \\
\mathbf{0 . 8 7 3} \\
\end{array}$} \\
\hline Available heat capacity & 0 & $0 \%$ \\
\hline Installed heat capacity & -14.923 & $-4.114 \%$ \\
\hline $\begin{array}{l}\text { Heat consumption for } \\
\text { your own needs }\end{array}$ & 0 & $0 \%$ \\
\hline Fuel consumption & -23.37 & $-17.28 \%$ \\
\hline $\begin{array}{l}\text { Supply of heat energy to } \\
\text { the grid }\end{array}$ & 116.16 & $14.6 \%$ \\
\hline Mass of emission & 9993.5 & $64.19 \%$ \\
\hline Object 7 & \multicolumn{2}{|c|}{0.794} \\
\hline Available heat capacity & -24.58 & $-25.445 \%$ \\
\hline Installed heat capacity & 0 & $0 \%$ \\
\hline $\begin{array}{l}\text { Heat consumption for } \\
\text { your own needs }\end{array}$ & -0.157 & $-9.235 \%$ \\
\hline Fuel consumption & 0 & $0 \%$ \\
\hline $\begin{array}{l}\text { Supply of heat energy to } \\
\text { the grid }\end{array}$ & 28.11 & $33.94 \%$ \\
\hline Mass of emission & 5143.7 & $26.005 \%$ \\
\hline Object 8 & \multicolumn{2}{|c|}{0.408} \\
\hline Available heat capacity & -6.43 & $-1.724 \%$ \\
\hline Installed heat capacity & 0 & $0 \%$ \\
\hline Heat consumption for & -5.55 & $-50.45 \%$ \\
\hline
\end{tabular}


M. Pokushko, A. Stupina, I. Medina-Bulo, E. Dresvianskii, A. Stupin, R. Kuzmich, I. Ruiga, L. Korpacheva

\begin{tabular}{|l|c|c|}
\hline your own needs & \multicolumn{1}{|c|}{} \\
\hline Fuel consumption & 0 & $0 \%$ \\
\hline $\begin{array}{l}\text { Supply of heat energy to } \\
\text { the grid }\end{array}$ & 627.735 & $144.843 \%$ \\
\hline Mass of emission & 8210.41 & $42.56 \%$ \\
\hline Object 9 & 0 & $0 \%$ \\
\hline Available heat capacity & 0 & $0 \%$ \\
\hline Installed heat capacity & 0 & $0 \%$ \\
\hline $\begin{array}{l}\text { Heat consumption for } \\
\text { your own needs }\end{array}$ & 0 & $0 \%$ \\
\hline Fuel consumption & 0 & $0 \%$ \\
\hline $\begin{array}{l}\text { Supply of heat energy to } \\
\text { the grid }\end{array}$ & 0 & $0 \%$ \\
\hline Mass of emission & \\
\hline
\end{tabular}

Thus, table 2 presents all the calculated indicators for clarity and the recommended values calculated according to the proposed methodology.

As can be seen from table 2, objects number 1 , numbers 3-5, and object number 9 of the centralized municipal heat supply system of Krasnoyarsk function as efficiently as possible. Therefore, their efficiency indicator is the maximum potential value and is equal to 1 . Therefore, no intervention is required in the operation of 5 objects of the city's centralized municipal heat supply system.

According to the data presented in table 2, you can also see that for objects with an efficiency indicator less than 1. Furthermore, there are deviations in the indicators of the inputs and outputs of the actual data and the recommended ones. Therefore, their efficiency coefficient is less than 1, respectively; improvements are required for the operation of these enterprises to improve the function of the centralized municipal heat supply system of Krasnoyarsk as a whole. In particular, for objects with the number 2 and numbers $6,7,8$, the performance indicators are less than 1 .

Below we will present a description of the performance indicators for these objects, calculated using the DEA method and presented in table 2. In order to achieve the recommended performance indicators of the input and output parameters for objects with number 2 and numbers $6,7,8$, it is recommended to make the following changes to the input and output indicators of these objects.
For object number 2, it is recommended to reduce the installed heat capacity in the grid by $72.57 \%$ without changing the available heat capacity and fuel consumption. As a result, reduce the heat consumption for your own needs by $69.383 \%$. In addition, it is recommended to increase the supply of heat energy to the grid by $6.034 \%$, and reduce the mass of emission by $11.5 \%$.

For object number 6 , it is recommended to reduce the installed heat capacity in the grid by $4.114 \%$ without changing the available heat capacity and heat consumption for their own needs. It is recommended to reduce fuel consumption by $17.28 \%$. It is recommended to increase the supply of heat energy to the grid by $14.6 \%$, and reduce the mass of emission by $64.19 \%$.

For object number 7 , it is recommended to increase the available heat capacity by $25.445 \%$ without changing the installed heat capacity in the grid and fuel consumption. Reduce the heat consumption for your own needs by $9.235 \%$. In addition, it is recommended to increase the supply of heat energy to the grid by $33.94 \%$, and reduce the mass of the emission by $26.005 \%$.

For object number 8 , it is recommended to reduce the available heat capacity by $1.724 \%$ without changing the installed heat capacity and fuel consumption. As a result, reduce the heat consumption for your own needs by $50.45 \%$. In addition, it is recommended to increase the supply of heat energy to the grid by $144.843 \%$, and reduce the mass of emission by $42.56 \%$.

Having studied the main technological processes for the objects of the centralized municipal heat supply system in the city of Krasnoyarsk, it is possible to identify the main recommendations for the modernization of boiler houses and heat and power plants. In order to achieve the recommended parameters of input and output indicators for objects with the number 2 and numbers $6,7,8$, it is recommended to modernize them through the following measures:

- use of raw materials with a higher heat transfer coefficient;

- the transition of boiler houses to hybrid operation (electricity generation for own needs); 
- the use of coal combustion products for commercial purposes (processing and reuse);

- the use of more efficient components and mechanisms of equipment;

- introduction of computerized lines;

- reduction of heat losses in the system through using new types of heat insulation.

\section{Conclusion}

Thus, this article proposed a method for evaluating the efficiency of a heat and power system by the DEA method. The essence of the DEA method and the main features of its application are described. The main problems of heat and power systems, which this technique is aimed at solving, are related. This method was tested at the centralized municipal heat supply system of the fuel and energy complex.

In recent years, DEA has been widely used to assess the effectiveness of complex systems in various fields. But, at the same time, the method was not used to evaluate the functioning efficiency of centralized municipal heat supply.

The DEA method helps to represent the efficiency for an object of a technical system as a numerical value by calculating one aggregated indicator for each of the objects, using input and output indicators. In the article, these indicators are presented as efficiency indicators in table 2 . For example, for objects number 1, numbers 35 , as well as object number 9 of the centralized municipal heat supply system, these indicators are the maximum possible and equal to 1 . And for objects with number 2 and numbers $6,7,8$, the efficiency indicators are less than 1.

This article analyzes the main indicators of input (available heat capacity, installed heat capacity, heat consumption for own needs, fuel consumption) and outputs (supply of heat energy to the grid and the mass of emission) of the studied enterprises. The recommended indicators of these values are presented, calculated using the DEA method to improve the system's functioning as a whole. Nine objects of the centralized municipal heat supply system from among boiler houses and heat and power plants of Krasnoyarsk were analyzed. Five objects of the system work in an optimal mode. Therefore, it is not necessary to carry out improvements for these enterprises.

Four objects of the centralized municipal heat supply system in Krasnoyarsk have efficiency indicators less than 1 . Therefore, the enterprises are not working in an optimal mode. It is necessary to improve the indicators of entrances and exits for these objects to improve the operation of the city's centralized municipal heat supply system as a whole.

Based on the results of the efficiency assessment using the DEA method, recommendations are proposed to improve the efficiency of the centralized municipal heat supply system of Krasnoyarsk for four inefficient facilities.

For object number 2, it is recommended to reduce the installed heat capacity in the grid by $72.57 \%$ without changing the available heat capacity and fuel consumption and reduce the heat consumption for your own needs by $69.383 \%$. In addition, it is recommended to increase the supply of heat energy to the grid by $6.034 \%$, and reduce the mass of emission by $11.5 \%$.

For object number 6 , it is recommended to reduce the installed heat capacity in the grid by $4.114 \%$ without changing the available heat capacity and heat consumption for their own needs. It is recommended to reduce fuel consumption by $17.28 \%$. In addition, it is recommended to increase the supply of heat energy to the grid by $14.6 \%$, and reduce the mass of emission by $64.19 \%$.

For object number 7 , it is recommended to increase the available heat capacity by $25.445 \%$ without changing the installed heat capacity and fuel consumption and reduce the heat consumption for your own needs by $9.235 \%$. In addition, it is recommended to increase the supply of heat energy to the grid by $33.94 \%$, and reduce the mass of the emission by $26.005 \%$.

For object number 8 , it is recommended to reduce the available heat capacity by $1.724 \%$ without changing the installed heat capacity in the grid and fuel consumption. Reduce the heat consumption for your own needs by $50.45 \%$. In addition, it is recommended to increase the 
supply of heat energy to the grid by $144.843 \%$, and reduce the mass of emission by $42.56 \%$.

Having studied the main technological processes for the objects of the centralized municipal heat supply system in the city of Krasnoyarsk, it is possible to identify the main recommendations for the modernization of boiler houses and heat and power plants. In order to achieve the recommended parameters of input and output indicators for objects with the number 2 and numbers $6,7,8$, it is recommended to modernize them through the following measures:

- use of raw materials with a higher heat transfer coefficient;

- transition of boiler houses to hybrid operation (electricity generation for own needs);

- the use of coal combustion products for commercial purposes (processing and reuse);

- the use of more efficient components and mechanisms of equipment;

- introduction of computerized lines;

- reduction of heat losses in the system through using new types of heat insulation.

The approbation of the DEA method on the objects of the centralized municipal heat supply system of the fuel and energy complex has not been presented in any scientific publication before. The research results presented in the article are of scientific and practical interest and can be used to improve the efficiency of heat and power system facilities. The DEA method of efficiency assessment proposed in the study is focused on practical application in various subject areas in which complex objects are organized in the form of hierarchical systems, in particular, in the field of centralized municipal heat supply systems of the fuel and energy complex (both in the management bodies of the industry as a whole, and in the control systems of individual boiler houses, heat and power plants and pumping stations). In addition, the obtained results are planned to be used for designing a decision support system based on the DEA method for energy system objects. We plan to propose a new approach to the study of complex hierarchical systems, which will be based on a new set of algorithms for the redistribution of resources in each subsystem of a hierarchical system in accordance with changes in input and output indicators, built on the basis of the DEA method. The complex of algorithms will help to develop recommendations for improving the integrated efficiency of each subsystem while improving the efficiency of the system as a whole based on changes in the indicators of inputs and outputs.

\section{References:}

[1] Pokushko M et al 2019 Application of data envelopment analysis method for assessment of performance of enterprises in fuel and energy complex Journal of Physics: Conf. Ser. 1351 012140.

[2] Pokushko $M$ et al 2020 Applying the Data Envelopment Analysis method for evaluating the efficiency of the complex system operations in fuel and energy companies Journal of Physics: Conf. Ser. 1515052039.

[3] Cooper W W, Seiford L M and Tone K (2000) Data Envelopment Analysis Boston: Kluwer Academic Publishers 318.

[4] Farrell MJ (1957) The measurement of productive efficiency. J R Stat Soc Ser A-G 120(3):253-290.

[5] Emrouznejad A, Yang G (2018) A survey and analysis of the first 40 years of scholarly literature in DEA: 1978-2016. Socio Econ Plan Sci 61(1): 4-8.

[6] Fiala P (2018) Project portfolio designing using data envelopment analysis and De Novo optimization. Cent Eur J Oper Res.

[7] Halická M, Trnovská M (2018) Negative features of hyperbolic and directional distance models for technologies with undesirable outputs. Cent Eur J Oper Res.

[8] Widiarto Indra and Emrouznejad A 2015 Social and financial efficiency of Islamic microfinance institutions: A Data Envelopment Analysis Application. Socio-Economic Planning Sciences 50 (1) 1-17.

[9] Foroughi AA, Shureshjani RA (2017) Solving generalized fuzzy data envelopment analysis model: a parametric approach. Cent Eur J Oper Res 25(4):889-905.

[10] Hatami-Marbini A, Saati S, Sajadi SM (2018) Efficiency analysis in two/stage structures using fuzzy data envelopment analysis. Cent Eur J Oper Res.

[11] Roháčová V 2015 A DEA based approach for optimization of urban public transport system. Cent Eur J Oper Res 23(1) 215-233.

[12] Holý V, Šafr K (2018) Are economically advanced countries more efficient in basic and applied research? Cent Eur J Oper Res.

[13] Jablonský J (2016) Efficiency analysis in multiperiod systems: an application to performance 
evaluation in Czech higher education. Cent Eur J Oper Res 24(2):283-296.

[14] Matulová M, Fitzová H (2018) Transformation of urban public transport financing and its effect on operators' efficiency: evidence from the Czech Republic. Cent Eur J Oper Res.

[15] Pastor JT, Aparicio J, Alcaraz J, Vidal F, Pastor D (2018) Bounded directional distance function models. Cent Eur J Oper Res.

[16] Takano Y, Ishii N, Muraki M (2017) Multiperiod resource allocation for estimating project costs in competitive bidding. Cent Eur J Oper Res 25(2):303.

[17] Shao Y, Bi G, Yang F, Xia Q (2018) Resource allocation for branch grid system with considering heterogeneity based on DEA method. Cent Eur J Oper Res.

[18] Qingyou Yan, Fei Zhao, u Wang, Guoliang Yang, Tomas Baležentis, Dalia Streimikiene (2019) The grid data envelopment analysis models for non-homogenous decision-making units based on the sun grid structure. Cent Eur J Oper Res. December 2019, Volume 27, pp 1221-1244.

[19] Toloo M, Tavana M, Santos-Arteaga FJ (2017) An integrated data envelopment analysis and mixed integer non-linear programming model for linearizing the common set of weights. Cent Eur J Oper Res.

[20] Branda M, Kopa M (2014) On relations between DEA-risk models and stochastic dominance efficiency tests. Cent Eur J Oper Res 22(1):13-35.

[21] Xie Q, Li Y, Wang L, Liu C (2018) Improving discrimination in data envelopment analysis without losing information based on Renyi's entropy. Cent Eur J Oper Res.

[22] Josef Jablonský, AliEmrouznejad, Mehdi Toloo (2018) Special issue on data envelopment analysis. Cent Eur J Oper Res.

[23] Antamoshkin, A. N., Morgunova O.N., Morgunov E.P. Methodology for studying the ef-fectiveness of complex hierarchical systems Bulletin of Sib. state. aerospace. Univ. 2006, 2 (9), 9-13. (In Russ.)

[24] Chernyshova G. Yu., Kovalev R. N. (2017) Application of Data Envelopment Analysis to assess the effectiveness of web-resources. Management Science 41(7):1172-1184.

[25] Bod'a M, Dlouhý M, Zimková (2018) Unobservable or omitted production variables in data envelopment analysis through unitspecific production trade-offs. Cent Eur J Oper Res.
[26] Meilisa Malik, Syahril Efendi and Muhammad Zarlis (2018) Data Envelopment Analysis (DEA) Model in Operation Management. IOP Conf. Ser.: Mater. Sci. Eng. 300012008.

[27] Morgunov E. P., Morgunova O. N. Promotion of the method of performance assessment of the Data Envelope Analysis systems in Russia. System analysis in design and management: Proc. XX Intern. Sci.-Prac. Conf., St. Petersburg, June 29 - July 1, 2016. St. Petersburg, 2016, 390-398. (In Russ.)

[28] Fu J (2018) Two-stage data envelopment analysis with undesirable intermediate measures: an application to air quality improvement in China. Cent Eur J Oper Res.

[29] Jablonský J (2018) Ranking of countries in sporting events using two-stage data envelopment analysis models: a case of Summer Olympic Games 2016. Cent Eur J Oper Res.

[30] Kitchenham, B., Madeyski, L., Budgen, D. et al. (2017) Robust Statistical Methods for Empirical Software Engineering. Empir Software Eng 22, 579-630.

\section{Contribution of individual authors to the creation of a scientific article (ghostwriting policy)}

Mariia Pokushko, Alena Stupina, Inmaculada Medina-Bulo conducted modeling and optimization of the methodology for evaluating the DEA method's centralized municipal heat supply system, organized experiments in section 3 , and prepared the publication.

Egor Dresvianskii and Roman Kuzmich were engaged in the formulation of research goals and objectives, organized the resource provision of information and reference materials for research, carried out the publication's editing.

Artem Stupin conducted the experiments in section 3.

Larisa Korpacheva and Irina Ruiga were responsible for statistics, were engaged in data storage and processing, carried out data analysis, processing, and visualization. In addition, they were involved in the design of the publication.

\section{Sources of funding for research presented in a scientific article or scientific article itself}

The reported study was funded by RFBR according to the research project № 20-37-90013.

\section{Creative Commons Attribution License 4.0}

(Attribution 4.0 International , CC BY 4.0)

This article is published under the terms of the Creative Commons Attribution License 4.0 https://creativecommons.org/licenses/by/4.0/deed.en $\underline{\text { US }}$ 